\title{
Investigating the Effect of Graduate Business Programs of the Schools of Business in Jordan in Forming Soft-Power Leadership Conceptualization among MBA Students
}

\author{
Faiz Hamad Zoubi ${ }^{1}$ \\ ${ }^{1}$ Professor, marketing and management, at Marketing Dep., College of Business, Mutah University, Amman, \\ Jordan \\ Correspondence: Faiz Hamad Zoubi, marketing and management, at Marketing Dep., College of Business, \\ Mutah University, Amman, Jordan.
}

Received: May 10, 2021

doi:10.5539/ibr.v14n7p19
Accepted: June 9, 2021

Online Published: June 16, 2021

URL: https://doi.org/10.5539/ibr.v14n7p19

\begin{abstract}
The main objective of the study is to explore the extent of the conceptualization of soft-power leadership among graduate business students, and the degree to which they apply the concept in their study programs in the Jordanian universities. In precise, to explore the effect of curriculums and courses, learning style, and the way the business program is managed in forming the concept of soft power leadership in students.

The analysis was extended to investigate the variation in the relationship between curriculums, learning style, and program management as independent variables and soft-power leadership concept as dependent variable due to the moderating variables gender, background education, and work sector. A sample of 350 students was drawn from two representative universities in Jordan. Data were collected by a self-designed questionnaire based on literature, Amos 21 was used in the analysis, and findings were as follows:

Students have positive attitudes toward soft-power leadership conceptualization with a satisfactory level of belief. Learning style and curriculums have been found to be of significant effect in soft-power conceptualization. This indicates that the American Model of Management Education (AMME) is applied in both curriculums and learning styles in business schools in Jordan.

With regards to the moderating effect of gender, background education, and job sector of students it was found that gender significantly affects the relationship between learning style and soft-power concept, and it does affect the relationship between program management and soft-power concept, Background education significantly affects the relationship between both curriculums and program management, and soft-power concept, while the job sector that students belong to in their work only affects significantly the relationship between program management and soft-power concept.
\end{abstract}

Keywords: soft power, business students, leadership, conceptualization, business programs, MBA, Jordan

\section{Introduction}

A leader is best when people barely know he exists, not so good when people obey and acclaim him; the worst is when they despise him (Lao-tsu, $630 \mathrm{BC}$ ). As the world experiences increasing globalization and democratization across boundaries and borders, and as the growth of emerging markets takes place in the world economy, research in management and leadership has to cope with and be cohesive in response to changes that occur in business firms all around the world.

Emphasis on human rights in politics and legislation are reflected by default in the way managers and leaders deal and communicate with their fellow workers and subordinates. Since leaders have to have a choice of how to lead, there may be different styles of leadership to choose from - for instance, coercing employees with threats, inducing them with payments and rewards, or attracting and persuading them - but in the end, a leader has to adopt what is suitable and chooses what will persuade and convince followers to do things based on their beliefs. Soft power is said to be the style to do the job as wanted (Nye, 2004) since it's the ability to shape preferences among employees and followers mainly in business firms, where it assumes commands to enforce decisions or attract others. Leaders in marketing have found themselves in a situation of needing to form an inclusive 
team-oriented style of leadership based on participative and integrative decision-making to achieve personal and professional success.

For two decades, research in leadership and business management has intensified its efforts to look for a way to enrich the custodian values of being soft in leading and to replace the hard style, in which commands are enforced through coercive approaches and a hierarchical style of leadership, with an inclusive style that welcomes diversified perspectives and views from everyone. The information revolution in the last two decades has altered business organizations in a way that has started to see more of a participative process in leadership, and hierarchies are being defeated by a network of contracts, contacts, and outsourcing in both public and private organizations.

\section{Background and Statement of the Problem}

Since higher education forms a vital cornerstone in the formation of soft-power, and conceptualization of soft-power is best formulated among intellectual segments of people, and since business education in Jordanian universities is mainly based on management principles of the American origin, the main purpose and/or the problem of this study is to explore the conceptualization of soft-power leadership among students in MBA programs in Jordanian universities concerning three domains: curriculum content, instructors' style of learning, and the style of the program's management and implementation. Students that were chosen for the study were enrolled in MBA executive business programs in schools of business. Most of them came from various sectors of businesses and managerial and leadership positions or were aiming to do so in the future. Based on Nye's (2002) assertion that business education is the main channel to reach the integrative modern values of democracy, equality of opportunity, social mobility, freedom, and open-mindedness, the study is conducted based on the assumption that graduate business students in the universities in Jordan have a weak attraction to the soft-power concept as a basic foundation in the American model of business education that is adopted by the schools of business in Jordan.

\section{Importance of the Study}

The concept as an infant soft-power management theory has spread to the levels of both the syllabus and enterprise, and is being practiced in political as well as in business domains, and since there are more than seven thousand business schools around the world deploying business principles based on the American philosophy, the question arises of whether graduates - and MBA students in particular - are forming an understanding of the concept of soft power as part of their intellectual and practical framework.

Soft-power has proved to be an effective approach to leadership and is less costly in accomplishing objectives since it has influenced and shaped business minds across the world due to its being an effective way to bring others to like what you have or believe in (Nye, 2004).

Based on this vital verification of the influence of the concept on management practices in the US and other countries, and based on the theoretical proof that higher education is a cornerstone in spreading the concept and advocating the application of soft power in the business context, this study is thought to be an important investigative effort to discover the contributive role of graduate business programs in Jordanian universities in forming soft-power as an international reference in business and management education.

In addition, the study is believed to be of great value to scholars, specialists, and leading practitioners, as well as business students. Therefore, the study may also form a solid background that will enable further studies to explore the concept in other domains, such as social sciences, other specializations, or undergraduate programs. It may be of great value too to conduct this type of study on managers and leaders in both private and public sectors, as well as on faculty members in business schools either in Jordan or in the Arab world.

\section{Objectives of the Study}

This study aims to explore the extent of the conceptualization of soft-power leadership among graduate business students and the degree to which they apply the concept in their management practices in their jobs. The research also aims to explore whether the business curriculums and courses, as well as the learning style and how graduate business programs are managed and implemented, have anything to do with forming the concept of soft power in students.

The study also aims to investigate if an effect exists on the relationship between the material taught (curriculums), the way they are introduced (learning style), and the way the program was managed and implemented on one side, and the formation of the soft-power concept in students due to the moderating effect of variables such as gender, background education, and work sector. Since the American Management Model of Education (AMME) was implicitly meant to be adopted in the Jordanian higher education system. Therefore, the 
researcher believes it worth's investigating the model application.

\section{Literature Review}

Management success depends on talent, trust, and soft-power (Evans \& Wolf, 2005). The term soft power was first used by Joseph Nye in the late 1980s and is now used by all scholars and leaders in political science and business management and leadership. It refers to the ability to get what you want through attraction rather than coercion or payment. When you can get others to want what you want, you don't have to spend so much time, money, or effort to move them in your direction. Seduction is more powerful than coercion, and many values to be adopted as democracy, human rights, and individual opportunities are more deeply seductive (Diplo, 2014). In contrast, hard power is the ability to affect the behavior of others, but through approaches that induce and coerce people through the practice of hierarchical commands, autocracy, threats, and the like (Nye, 2006). Hard-power differs from soft power, and the distinction between them is stated as follows: hard-power (or command) and soft-power (or co-option) behaviors range along a spectrum from coercion to economic inducement to agenda-setting to the pure attraction (Nye, 2004). Experts and practitioners in business leadership refer to soft-power as a feminine style, by which leadership is more cooperative, participative, integrative and co-opts the behavior of followers, while hard-power is a patriarchal style, by which leadership is more assertive, competitive, autocratic and is focused on commands (Nye, 2006). Although the concept has been around for almost 20 years, the question arises of where leadership theory currently stands on the roles of soft-power and hard-power.

We may claim that Joseph Nye is the father of the soft-power concept since he created the term in 1991, and since the concept has become intellectualized and conceptualized, and the term is used in political science and business management. Nye (2004) looked at the power from different perspectives, and when he qualified power with the adjective of soft, he saw it as just like love - pliable, flexible, and yielding, and more prominent in practice and experience than in definition or measurement. On the macro or country level, Nye dealt with the concept of soft-power in a different context from the way power was used as hard, when leaders looked at themselves as more able to get their followers to do what they would not otherwise do and accomplish the end state of a job even if they did not have the means to do so. In this context, hard power was viewed by (Lukes, 2005) in three dimensions: behavior, decision-making and conflict; the non-decision-making process as the resistance to the decision; and the political agenda. Lukes (2011) viewed power as "the power to prevent people from having grievances by shaping their perceptions, cognitions, and preferences in such a way that they accept their roles in the existing order of things". In contrast, Nye looked at power as a reliance on the ability to shape and reform the preferences of followers to make them want what they have (Nye, 1990).

Other arguments related to smart-power have been brought to the debate that combines certain elements from hard-power and soft-power in a mutual enforcement to lead effectively and efficiently in a way that is more suitable in diplomatic, political, and relation-forging areas. According to Wilson III (2008), the interest in smart-power reflects two contemporary trends: structural and long-term; and conjunctural, which is driven mainly by the American Administration, since the American Administration is lacking in the use of smart-power, and countries around the world are using sophisticated types of diplomatic and political power.

\subsection{Soft-power in Different Countries}

The soft-power concept has become popular outside the US. China and Taiwan were the first countries to show an interest and to look at the concept differently. For example, Wang \& Chung $\mathrm{Lu}$ (2008) found that soft power is seen in China as an intangible, non-quantifiable, non-material, or spiritual power. More specifically, they interpreted it as the ability to persuade others with reasons and to convince them with moral principles, equating soft power with the power of subduing enemies without fighting them. It was based on ancient Chinese philosophies and mainly relied on the historical notion of "doing it in a kingly way rather than in a bullying way", which means setting a moral example rather than doing things by brute force. In Taiwan, the interpretation of the concept of soft-power was different and was closer to the way Nye has looked at it and defined it. The Taiwanese have seen it as a leadership method that involves changing others' preferences through persuasion, and many have looked at it as co-optive power or as an ability to shape others. It is also defined as an umbrella concept that includes power elements rather than strengths and punitive sanctions, which enhance attractiveness. These elements include culture, political systems, and openness of the information society, education, ideology, and economic models, as well as the competitiveness.

The concept of soft power in Russia was different since culture and philology have played a big role in the definition of the concept. Dougherty (2013) has suggested that, while the Western concept of soft power is based on attraction, the Russian concept is based on projection, using some level of influence as structured instruments 
of public diplomacy. This may be done through assisting in international development, providing international humanitarian cooperation, developing a network of Russian scientific and cultural centers abroad, and strengthening the Russian language. It also includes asserting the objectives of modern Russia and its material and spiritual potential, with the help of religious organizations and scientific, cultural, informational, and humanitarian areas. For the Russians to have a sound soft power concept of their own, and as the concept needs transparency and democratic measures to build its attractiveness internally and externally, they have to introduce new reforms of liberalization that focus on a liberal economy and a democratic political system (Karpowicz, 2012).

\subsection{Soft-Power in Education:}

When Nye (1990) emphasized soft power as the magic concept of attraction on all levels - political and diplomatic, as well as in leadership and management - he was trying to say that culture and values are the most important foundations on which to build the image that makes others want to do what you want, without making them do what you want. So education is considered to be the best tool for making others admire your way of doing things. Students from all over the world who have been educated in the US or in countries whose system of education is based on the American style of management would be the best way to attract and seduce people to apply the soft concept in other areas, whether that is politics, diplomacy, or foreign relations.

In his literature on the subject, Nye said that the main theme of soft-power to do the job in your way is invested or rested in its ability to shape the preferences of others. Even though soft-power embraces three dimensions culture, political values, and foreign policy - the great benefit in education comes from the first dimension, which is culture, and its projection on educational programs at all levels. The information revolution that has taken place in education as well as the transition of curriculums across the world has done a tremendous job in enhancing soft-power.

China is making great efforts to promote its soft-power philosophy through educational programs and has emphasized that in its strategic plans. China is expanding rapidly in using English-taught university programs and is encouraging students from all over the world to study in China by offering accommodation and scholarships. The US and European countries are investing in their programs to encourage more students to study in China. Although the Chinese are trying to invest in their type of soft-power and promote it through education, the Chinese method of soft-power is not skillful.

Soft power in China is meant to be deployed by promoting the national interest using persuasion and attraction in their educational programs, which are introduced overseas in the form of high-profile programs, mainly in Latin America and Africa. Billions of dollars are spent on these programs. The spread of soft-power by the Chinese has been supported at the highest level. President Hu Jintao advanced the concept of soft-power in his speech at the $17^{\text {th }}$ National Congress of the Communist Party of China.

China's higher education is shifting, widening, and diversifying along its Silk Road, and this is aligned with its new economic policy, which is aimed at innovating its large-scale manufacturing through the use of soft-power among neighboring countries as well as internationally (Marijk, 2016). Soft-power in the American version, as Nye stated, is always the ability to attract and co-opt, which has been adopted by the Chinese, but in addition to hard-power and the use of coercion as well as the use of money to attract others. This was carried on in serious discussion along with the Western concept of soft power (Shambaugh, 2013).

The EU also used soft-power with others for cooperative purposes. Science and technology were the basis of Europe's cooperation agreement with other countries to facilitate interactions with the rest of the world in all areas. The vehicle for this scientific cooperation was a seven-year framework program called Horizon 2020, which was developed by EU members and other selected countries (UNESCO, Media Services, 2017).

The UK has strengthened its efforts in using soft-power alongside hard-power to build positive cooperation with other countries around the world, as well as locally since society to some degree has become culturally diversified because of immigration. As a response to newly emerging challenges facing the UK, they considered soft-power to be a good tool for building cooperative bridges with other countries through establishing educational programs among young people in key countries to improve their employability, education, and skills, and thus their stake in society. So through soft-power, the UK's trade with others might be strengthened too. Therefore, as a method of future-proofing, the UK is intending to use soft-power alongside hard-power to build soft-power assets as a strategic priority (Dubber, 2015).

A study conducted by (O'Brien, 2011) to investigate the influence of the American Model of Management Education (AMME) on Indian MBA students in management programs in three domains: the private circle, 
which illustrates the Western influence; the work environment, which shows the application of principles taught in business schools; and the classroom, which reflects the curriculum. The study found that the American model of education still dominates Indian MBA programs, but with some regional adaptation. The soft power of AMME remains dominant and expansionist, and one of the dominant elements of AMME is a new bipolarity between knowledge producer countries and knowledge users. Although the study found a dialectical tension between the European and the American models, in all three fields - private, enterprise, and school - the dominant influence was the AMME. Bieber \& Martens (2011) concluded in their study that in Switzerland, PISA's platform for transnational communication enabled policy learning at the expert level, thus leading to a rather high degree of policy convergence, and it was not the same in the US, where PISA was regarded as one of many studies assessing the performance of the education system.

Since an instructor or teacher is meant to be the backbone of any educational program and the main bearer of responsibility for its success in reaching its objectives, he has to be a leader of his class. Team leaders, department chairs, associate leaders, and curriculum developers are also considered to be capable of enabling change among their students (Livingston, 1992). In this context, to be effective leaders in their careers, teachers have to have the skills of building trust in their students and developing support, diagnosing organizational conditions, dealing with the process, managing their work, and building skills and confidence in their students (Dimock \& McGree, 2015). Therefore, teachers' or instructors' responsibility is to convert research into actions in class, support their colleagues and faculty, foster technology-based cooperation with students and faculty, and promote equality.

Due to the vast economic, political, and military changes that have taken place throughout the world, and because of the rise of the emerging BRICS countries, which formed serious competition to the US, decision-makers were forced to change the rules of the game. In this regard, Nye emphasized three pillars to rely on for the use of soft power: culture, political values, and foreign policy, and higher education (Nye, 2004).

\section{Conceptual Framework of the Study}

Consistent with the problem and purpose of the study and based on a review of the literature, the researcher has limited the research to the soft-power management concept and its main dimensions, based on Joseph Nye's classification of the soft-power concept. The researcher limited the scope of the study to the four principal dimensions and, where appropriates, their sub-dimensions, as follows:

1. Emotional intelligence: Self-awareness, social awareness.

2. Vision.

3. Rhetoric: (Ethos) personal and professional credibility. (Pathos) creating the right emotional environment. (Logos) argumentation.

4. Non-verbal communication: Body language, tonality, physical setting.

The design of the study has taken the form of association and effect (causal relationship) and variation in effect between the three independent variables - curriculum content, style of learning, and the way the program is managed and implemented - and the dependent variable, which is the conceptualization of soft-power leadership among students based on the four dimensions of the soft-power concept: emotional intelligence, vision, rhetoric, and non-verbal communication. The idea that stands behind this design is to explore the extent of belief and intellectual involvement in the soft-power management concept among students and the quality of graduate business programs in the Jordanian universities in forming such a concept. Some job-related and demographic variables are considered in the study to play the role of moderating variables to explore their effect on the assumed causal relationship. The moderating variables are the type of sector or industry (either private or public sector) that the student's job related to, the student's background in terms of their BA degree, and gender. 


\subsection{Model of the Study:}

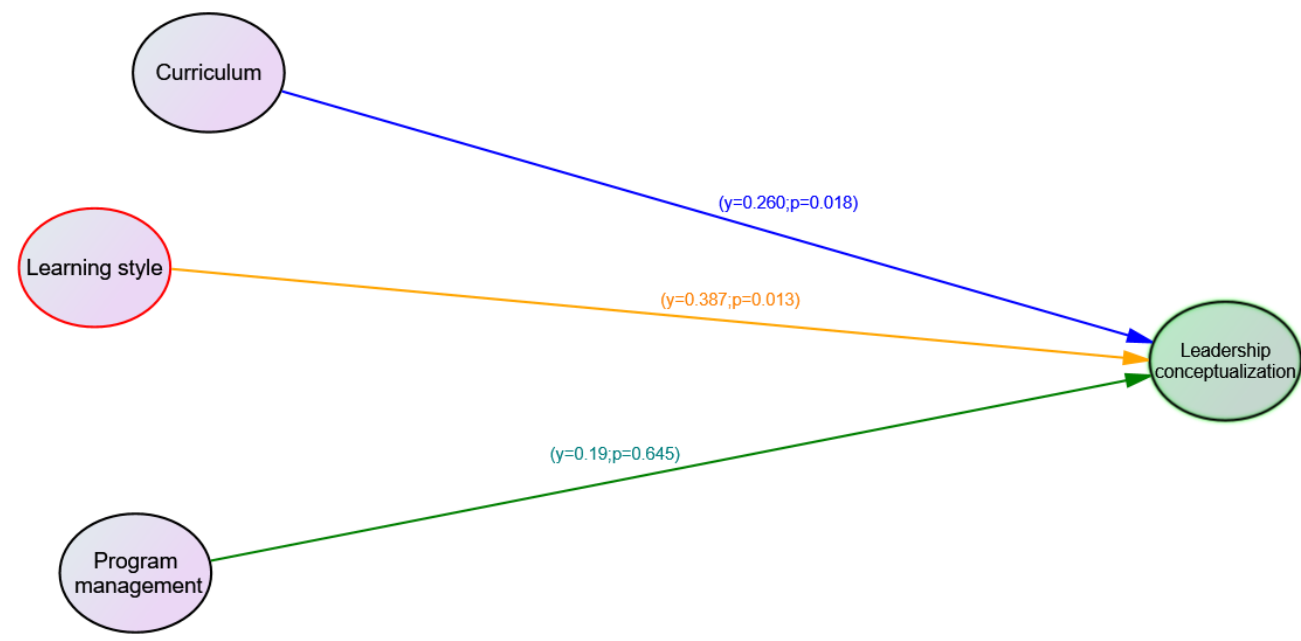

Figure 1. The Conceptual Model

\subsection{Hypotheses of the Study}

The following null hypotheses have been designed to investigate the effect of curriculum content, style of learning, and style of program management and implementation (which, for ease of reading, will sometimes be referred to as program management/implementation) on soft-power leadership conceptualization among MBA students in Jordanian universities:

H0 1: The independent variables curriculum content, learning style, and program management and implementation have no significant effects on the dependent variable soft-power leadership conceptualization among MBA students. This hypothesis is broken down into its minor hypotheses, as follows:

H0 1.1: There is no significant effect of curriculum content on soft-power leadership conceptualization among MBA students.

H0 1.2: There is no significant effect of learning style on soft-power leadership conceptualization among MBA students.

H0 1.3: There is no significant effect of program management and implementation on soft-power leadership conceptualization among MBA students.

H0 2: The moderating variable gender has no significant effect on the causal relationship between the independent variables (curriculum content, learning style, and program management and implementation) and the dependent variable (soft-power leadership conceptualization among MBA students). This hypothesis is broken down into its minor hypotheses, as follows:

H0 2.1: There is no significant effect of gender on the causal relationship between curriculum content and soft-power leadership conceptualization among MBA students.

H0 2.2: There is no significant effect of gender on the causal relationship between learning style and soft-power leadership conceptualization among MBA students.

H0 2.3: There is no significant effect of gender on the causal relationship between program management/implementation and soft-power leadership conceptualization among MBA students.

H0 3: The moderating variable background education has no significant effect on the causal relationship between the independent variables (curriculum content, learning style, and program management and implementation) and the dependent variable (soft-power leadership conceptualization among MBA students). This hypothesis is broken down into its minor hypotheses, as follows:

H0 3.1: There is no significant effect of background education on the causal relationship between curriculum content and soft-power leadership conceptualization among MBA students.

H0 3.2: There is no significant effect of background education on the causal relationship between learning style 
and soft-power leadership conceptualization among MBA students.

H0 3.3: There is no significant effect of background education on the causal relationship between program management/implementation and soft-power leadership conceptualization among MBA students.

H0 4: The moderating variable work sector has no significant effect on the causal relationships between the independent variables (curriculum content, learning style, and program management and implementation) and the dependent variable (soft-power leadership conceptualization among MBA students). This hypothesis is broken down into its minor hypotheses, as follows:

H0 4.1: There is no significant effect of the work sector on the causal relationship between curriculum content and soft-power leadership conceptualization among MBA students.

H0 4.2: There is no significant effect of the work sector on the causal relationship between learning style and soft-power leadership conceptualization among MBA students.

H0 4.3: There is no significant effect of the work sector on the causal relationship between program management/implementation and soft-power leadership conceptualization among MBA students.

\subsection{Operational Definition of Variables}

Soft-power leadership: This is the art of persuasion and personal magnetism, or the ability of the leader (in our case the college instructor) to influence his followers (students) by connecting with them physically, emotionally, and intellectually. In other words, it's the leader's charisma (Nye, 2006).

Curriculum content: This is the material used in class, such as textbooks, related reading, exercises, cases, and other requirements for the course, such as term papers, research, and projects.

Learning style: This is the style that instructors employ in their classes, including the proper use of emotional intelligence (self-awareness and social awareness), rhetoric, and verbal and non-verbal languages.

Program management and implementation: This is how the MBA program was designed by the department, including its vision, objectives, and philosophy; how the program is managed and implemented in terms of course availability and timing; and the sequence of courses and interdependency.

Emotional intelligence: This is divided into two dimensions: self-awareness, in which the leader (instructor) reflects on his emotional reactions in terms of self-management; and social awareness, in which he uses empathy in understanding followers' (students') emotional reactions in terms of their management.

Vision: This is the ability of the leader (instructor) to form and articulate an inspiring picture of the concept or subject of concern, as well as using the right plan and policy in his relationship with employees (students).

Rhetoric: This is the personal and professional ability of the leader (instructor) to persuade his followers (students) through the use of an emotional environment and argumentation in handling issues or topics.

Non-verbal communication: This is the leader's (instructor's) ability to use body language, in terms of facial expressions, eye contact, gestures, posture, and body movements; tonality, in terms of intonation, pitch, and tone of voice; and physical setting - or, as it's also called, the hidden message - which consists of non-verbal symbols, physical signs, and images.

\section{Methodology of the Study}

\subsection{Type of the Study}

Concerning the objectives and hypotheses of the study, the descriptive-analytical method was used to explore soft-power leadership conceptualization among the students of Jordanian universities based on the survey approach to investigate the attitudes and perceived understanding of the issue of the study.

\subsection{Population and Sample of the Study}

The population of the study was MBA students enrolled in Jordanian universities. The total number of Jordanian universities listed by the Ministry of Higher Education of Jordan was 30, which varied between small, medium, and large based on the number of students according to arbitrary regional measures. Since the total number of MBA students was too large to conduct the study for all universities, two universities were selected: the University of Jordan, the largest Jordanian university, which is located in the capital, Amman; and Mutah University, a midsized university located in the southern region of Jordan. These two universities are assumed by the researcher to be representative of all Jordanian universities, since no big variations exist between students in terms of culture, family education, or background, as, aside from a few students from the Gulf countries, almost all the students on the program were Jordanian citizens. Four hundred questionnaires were distributed randomly 
by hand using a convenient sampling method to MBA students in the two universities, which was assumed to be sufficient to be representative of the population to be able to generalize the results and findings. Around 375 questionnaires were returned, 25 questionnaires were excluded, leaving 350 questionnaires that were complete and suitable for analysis.

\subsection{Data Collection and Scaling}

A multifactor questionnaire was developed by the researcher based on related literature using a five-point Likert-type scale because of its suitability for this type of study. The choices of answers were Very High, High, Average, Low, or Very low with weights of 5, 4, 3, 2, and 1 respectively. The questionnaire was divided into five parts. The first part is to investigate the demographic variables of the subjects in terms of gender, education background, and work sector. The second part was related to students' perceptions of soft-power leadership (as the dependent variable of the study) and how they conceptualize it in their work. Twelve questions were designed to answer this issue (from 1 to 12 ). The three remaining parts contained questions related to the independent variables, arranged as follows. The third part was about students' perceptions of the suitability of the content of the curriculum of the MBA program concerning the issue of the study. Thirteen questions were designed to answer this issue (from 13 to 25). The fourth part was about the style of learning in the program, and fifteen questions were designed to answer this issue (from 26 to 40). The fifth part was about the managerial style and suitability of how the MBA program is directed and implemented. Twelve questions were designed to answer this issue (from 41 to 52).

\subsection{Validity and Reliability}

Table 1. Construct Reliability for all Variables

\begin{tabular}{lll}
\hline Construct & Composite Reliability & CR \\
\hline $\mathbf{D}$ & 0.837 & \\
$\mathbf{C}$ & 0.850 & \\
$\mathbf{L}$ & 0.874 & \\
$\mathbf{P}$ & 0.891 & \\
\hline
\end{tabular}

D: Soft-power concept. C: Curriculum content. L: Learning style. P: Program management.

To ensure the validity and suitability of the questionnaire to the issue of the study, it was discussed with colleagues and specialists to confirm its adequacy in measuring the concepts.

A reliability test was carried out on the data to measure the stability and consistency of the items within the questionnaire.

A construct reliability test was run via composite reliability (CR) (Anderson \& Garbing, 1988). As indicated in table 1, the extracted value of $\mathrm{CR}$ for all variables was above the minimum required level of 0.70 . The values for the variables $\mathrm{D}, \mathrm{C}, \mathrm{L}$, and $\mathrm{P}$ were $0.873,0.850,0.874$, and 0.891 respectively. The results confirmed the suitability of the data for analysis since all values were above the minimum required values.

\section{Descriptive Analysis and Results of Hypotheses Testing}

\subsection{Descriptive Analysis}

Table 2. Percentage and Frequency of Demographic Variables

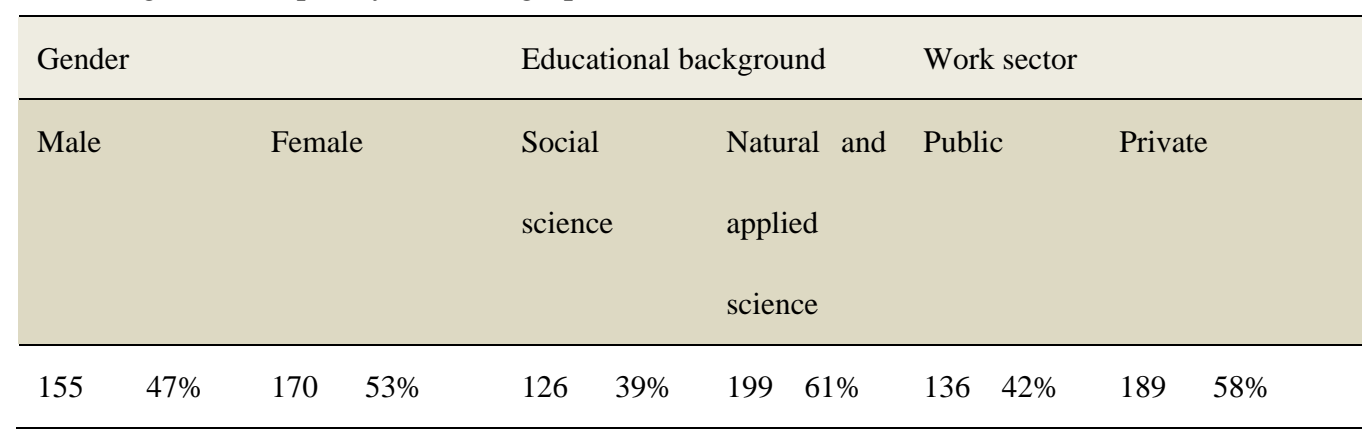

As stated in table (2), in terms of their demographic variables, around $53 \%$ of the respondents were female students and $47 \%$ were males. Those who had studied for an undergraduate degree in natural and applied scientific specialties constituted around $61 \%$ compared to $39 \%$ who came from social sciences background. Concerning their work sector, $58 \%$ of the respondents were holding jobs in the private sector compared to $42 \%$ in the public sector. 
Table 3. Descriptive Statistics of Variables

\begin{tabular}{|c|c|c|c|c|c|c|c|c|c|}
\hline Variables & $\begin{array}{l}\mathrm{N} \\
\text { Statistic }\end{array}$ & $\begin{array}{l}\text { Minimum } \\
\text { Statistic }\end{array}$ & $\begin{array}{l}\text { Maximum } \\
\text { Statistic }\end{array}$ & $\begin{array}{l}\text { Mean } \\
\text { Statistic }\end{array}$ & Std. Error & $\begin{array}{l}\text { Std. } \\
\text { Deviation } \\
\text { Statistic }\end{array}$ & $\begin{array}{l}\text { Variance } \\
\text { Statistic }\end{array}$ & $\begin{array}{l}\text { Skewness } \\
\text { Statistic }\end{array}$ & Std. Error \\
\hline Soft power & 325 & 1.50 & 5.00 & 3.8056 & .02835 & .51103 & .261 & -.314 & .135 \\
\hline Curriculum & 325 & 1.00 & 4.85 & 3.4774 & .02983 & .53784 & .289 & -.475 & .135 \\
\hline Learning & 325 & 1.36 & 5.00 & 3.5031 & .03050 & .54979 & .302 & -.072 & .135 \\
\hline Program & 325 & 1.50 & 5.00 & 3.4036 & .03604 & .64972 & .422 & -.212 & .135 \\
\hline $\begin{array}{l}\text { Valid } \\
\text { (listwise) }\end{array}$ & $\mathrm{N}_{325}$ & & & & & & & & \\
\hline
\end{tabular}

Table (3) illustrates the results of the descriptive statistics for the dependent variable soft-power leadership conceptualization among students and the independent variables curriculum content, learning style, and program management and implementation. The scores ranged between low (1.00) and high (5.00). The lowest was for curriculum content, and the highest was for the other two independent variables, learning style, and program implementation, as well as for soft-power leadership conceptualization. The highest positive mean score was for soft-power leadership (3.8056) and the lowest positive mean score was for program management and implementation (3.4036), which means subjects' answers for all variables were above average. This indicates that they are positive in their attitudes toward the way the MBA program is managed and implemented, as well as toward the way instructors are conducting the teaching process through the use of suitable curriculum content to enhance soft-power conceptualization among students.

\subsection{Test of Hypotheses}

Hypothesis H01: "The independent variables curriculum content, learning style, and program management and implementation have no significant effects on the dependent variable soft-power leadership conceptualization among MBA students."

AMOS 21 was used to calculate the correlation coefficients of the causal relationships between the three independent variables (curriculum content, learning style, and program management and implementation) and the dependent variable (soft-power leadership among students) separately, to explore the extent and patterns of the relationships (Anderson \& Gerbing, 1988; Byme, 2010; and Hair et al., 2010).

Table 4. Results of Standardized Estimates of Structural Model

\begin{tabular}{|c|c|c|c|}
\hline Path & $\begin{array}{ll}\begin{array}{l}\text { Path } \\
\text { coefficients }\end{array} & (\mathbf{R}) \\
\end{array}$ & P-value & Significance [YES/NO] \\
\hline$C \rightarrow D$ & 0.260 & 0.018 & YES \\
\hline$L \rightarrow D$ & 0.387 & 0.013 & YES \\
\hline $\mathbf{P} \rightarrow \mathbf{D}$ & 0.19 & 0.645 & NO \\
\hline
\end{tabular}

C: Curriculum > Soft-power. L: Learning > Soft power. P: Program > Soft power.

As a base concept of the model, the results in table (4) show that the R-values for the path coefficients were 0.260 (with a P-value of 0.018) for curriculum content with soft-power leadership, 0.387 (with a P-value of 0.013 ) for learning style, and 0.19 (with a P-value of 0.645 ) for program management and implementation.

Based on these results, hypothesis HO1/1 ("There is no significant effect of curriculum content on soft-power leadership conceptualization among MBA students") is rejected and the alternative hypothesis is accepted since the P-value of 0.018 was lower than the base decision of the value of Sigma P $>0.05$, which means there's a significant effect of curriculum content on soft-power leadership conceptualization among MBA students.

Referring to the same table and concerning the second minor hypothesis, HO1/2 ("There is no significant effect of learning style on soft-power leadership conceptualization among MBA students"), the hypothesis is also rejected and the alternative hypothesis is accepted since the P-value of 0.013 was lower than the base decision of Sigma, which means there is a significant effect of learning style on soft-power leadership conceptualization among MBA students.

As illustrated in the same table, the third minor hypothesis, HO1/3 ("There is no significant effect of program management and implementation on soft-power leadership conceptualization among MBA students"), is accepted, since the P-value of 0.645 is higher than the base decision of Sigma, which means there is no significant effect. 
Hypothesis H02: "The moderating variable gender has no significant effect on the causal relationship between the independent variables (curriculum content, learning style, and program management and implementation) and the dependent variable (soft-power leadership conceptualization among MBA students)."

Table 5. Results of Standardized Estimates

\begin{tabular}{lllll}
\hline & Male & & Female & \\
\hline Hypothesized path & Standardized estimate & P-value & Standardized estimate & P-value \\
C $\rightarrow$ D & 0.30 & 0.033 & 0.182 & 0.245 \\
L $\rightarrow$ D & 0.127 & 0.513 & 0.671 & 0.007 \\
P $\rightarrow$ D & 0.208 & 0.211 & 0.561 & 0.005 \\
\hline
\end{tabular}

C: Curriculum content. L: Learning style. P: Program management. D: Soft power.

Tables (5) and (6) illustrate the results of the analysis concerning the minor hypotheses of this main hypothesis. Table 5 shows that the sample was divided into two categories - male and female - to examine the moderating effect of gender on the causal paths of the relationships between the three independent variables and the dependent one. The extracted coefficient values for the three paths were different for males and females. The effect of curriculum content on soft-power leadership conceptualization was significant (with a P-value of 0.033 ) among males but was not significant among females. In contrast, the effects of both learning style and program management/implementation on soft-power leadership conceptualization were not significant among males, but were significant among females (with P-values of 0.007 for learning style and 0.005 for program management and implementation).

This proves there is an effect as well as a difference in effect in the independent variables' relationships to the dependent variable that can be attributed to gender. An investigation was undertaken into the moderating effect of gender on the causal relationships between the independent variables and the dependent variable.

Table 6. Result of Moderating Effects of Gender ( $\chi^{2}$ Difference Test)

\begin{tabular}{lllll}
\hline $\begin{array}{l}\text { Unconstrained } \\
\text { model }\end{array}$ & $\chi^{2}$ & DF & $\Delta \chi^{2}$ & P-value \\
$\begin{array}{l}\text { Constrained } \\
\text { model }\end{array}$ & 4400.529 & 2536 & & \\
$\begin{array}{l}\text { Constrained paths } \\
\text { b } \rightarrow \text { D }\end{array}$ & 4501.866 & 2587 & 101.337 & 0.000 \\
$\mathrm{~L} \rightarrow \mathrm{D}$ & & & & \\
$\mathrm{P} \rightarrow \mathrm{D}$ & 4405.987 & 2530 & 5.458 & Non-significant \\
& 4425.147 & 2530 & 24.618 & 0.005 \\
\hline
\end{tabular}

C: Curriculum. L: Learning. P: Program management. D: Soft power.

The $\chi 2$ of the unconstrained base model was compared with the $\chi 2$ of the constrained model. As shown in table 6 , $\Delta \chi 2$ value was 101.337 , and the P-value $(0.000)$ was significant. This means there is a difference between the two groups (males and females), which indicates a possible difference at the paths level. One path coefficient was constrained to be equal over the models of the two types (males and females), and the value of $\chi^{2}$ for the new model with the constrained path was then compared with the value of $\chi 2$ for the unconstrained base model (Wang \& Shih, 2009, Taylor \& Tadd, 1995).

Table 6 illustrates significances among males' and females' effect on the causal relationship between learning style and soft-power leadership conceptualization $\left(\Delta \chi^{2}=24.618\right)$ at P-value $<0.005$. In addition, gender was found to have a significant moderating effect on the relationship between program management/implementation and soft-power conceptualization, with females having the strongest effect $\left(\Delta \chi^{2}=11.829\right.$ at P-value <0.030). Meanwhile, there was no significant moderating effect attributed to differences in gender on the causal effect of curriculum content on soft-power leadership conceptualization $\left(\left(\Delta \chi^{2}=5.458\right.\right.$ at P-value $\left.<0.310\right)$.

Based on these results, it can be said that hypothesis HO2/1 ("There is no significant effect of gender on the causal relationship between curriculum content and soft-power leadership conceptualization among MBA students") is accepted, since the P-value was 0.310 , which means there is no effect of gender on the causal relationship between curriculum content and soft-power leadership conceptualization. The results also indicated that the minor hypothesis $\mathrm{HO} 2 / 2$ ("There is no significant effect of gender on the causal relationship between 
learning style and soft-power leadership conceptualization among MBA students") is rejected and the alternative hypothesis is accepted since the P-value was 0.005 , and the hypothesis HO2/3 ("There is no significant effect of gender on the causal relationship between program management/implementation and soft-power leadership conceptualization among MBA students") is also rejected and the alternative hypothesis is accepted since the P-value was 0.030 . This means that gender has a significant effect on the causal relationships between both learning style and soft-power leadership conceptualization, and program management/implementation and soft-power leadership conceptualization.

Hypothesis H03: "The moderating variable background education has no significant effect on the causal relationship between the independent variables (curriculum content, learning style, and program management and implementation) and the dependent variable (soft-power leadership conceptualization among MBA students)." Analysis was conducted on the minor three hypotheses derived from this main hypothesis separately.

Table 7. Results of Standardized Estimates

\begin{tabular}{lllll}
\hline & Social science & Natural science \\
\hline Hypothesized path & Standardized estimate & P-value & Standardized & P-value \\
& & & estimate & 0.021 \\
$\mathrm{C} \rightarrow \mathrm{D}$ & 0.084 & 0.608 & 0.405 & 0.577 \\
$\mathrm{~L} \rightarrow \mathrm{D}$ & 0.535 & 0.031 & 0.168 & 0.684 \\
$\mathrm{P} \rightarrow \mathrm{D}$ & 0.187 & 0.285 & 0.098 & \\
\hline
\end{tabular}

Tables (7) and (8) illustrate the results of the analysis for the three minor hypotheses. Concerning the effect of background education on the causal relationships between the independent variables and the dependent variable, table (7) shows that the sample was divided into two categories: social sciences and natural sciences. The extracted coefficient values for the three paths of causal relationships were different for the two categories. These differences in the main predictors of $\mathrm{D}(\mathrm{C}, \mathrm{L}$, and $\mathrm{P})$ are attributed to the moderating variable educational background. The only significant effect was among natural sciences students, with a P-value of 0.021 .

Table 8. Result of Moderating Effects of Educational Background ( $\chi 2$ Difference Test)

\begin{tabular}{|c|c|c|c|c|}
\hline & $x^{2}$ & DF & $\Delta \chi^{2}$ & P-value \\
\hline $\begin{array}{l}\text { Unconstrained base } \\
\text { model }\end{array}$ & 4424.28 & 2536 & & \\
\hline $\begin{array}{l}\text { Constrained base } \\
\text { model }\end{array}$ & 4489.27 & 2587 & 64.99 & 0.005 \\
\hline Constrained paths & & & & \\
\hline $\mathrm{C} \rightarrow \mathrm{D}$ & 4435.578 & 2530 & 11.298 & 0.010 \\
\hline $\mathrm{L} \rightarrow \mathrm{D}$ & 4427.188 & 2530 & 2.908 & 0.125 \\
\hline $\mathrm{P} \rightarrow \mathrm{D}$ & 4434.987 & 2530 & 10.707 & 0.040 \\
\hline
\end{tabular}

To investigate the moderating effect on the causal relationships between the independent variables and the dependent variable, further analysis was conducted. As shown in table 8 , the $\Delta \chi^{2}$ value was 64.99 and was significant at $\mathrm{P}$ level (0.005), which means there are significant differences between the educational background groups, and these predict significant differences at the path levels. One of the paths coefficients was constrained to be equal over the models of the two categories (social science and natural science), and the value of the $\chi^{2}$ for the new model with the constrained path was then compared with the $\chi^{2}$ value for the unconstrained base model (Wang \& Shih, 2009, Taylor \& Todd, 1995).

In the same table, the strongest effect of the educational background was in the path of $C$ to $D\left(\Delta \chi^{2}=11.298\right.$ at $\mathrm{p}<0.010)$. Educational background was also able to moderate the causal relationship between $\mathrm{P}$ and $\mathrm{D}$, where the strongest effect was found to be in the case of social science background $\left(\Delta \chi^{2}=10.707\right.$ at $\left.p<0.040\right)$. Meanwhile, there was no significant moderating effect of educational background on the causal relationship between $\mathrm{L}$ and $\mathrm{D}$ $\left(\Delta \chi^{2}=2.908\right.$ at $\left.\mathrm{p}<0.125\right)$.

Based on these results, hypothesis HO3/1 ("There is no significant effect of background education on the causal relationship between curriculum content and soft-power leadership conceptualization among MBA students") and hypothesis HO3/3 ("There is no significant effect of background education on the causal relationship between program management/implementation and soft-power leadership conceptualization among MBA students") are rejected and the alternative hypotheses are accepted since the P-values are 0.010 and 0.040 
respectively. On the other hand, HO3/2 ("There is no significant effect of background education on the causal relationship between learning style and soft-power leadership conceptualization among MBA students") is accepted since the P-value is 0.125 . This means that the causal relationships between the two independent variables curriculum content and program management/implementation and the dependent variable soft-power leadership conceptualization are affected significantly by the moderating variable background education, while there is no significant effect in the case of the third independent variable, learning style.

Hypothesis H04: "The moderating variable work sector has no significant effect on the causal relationships between the independent variables (curriculum content, learning style, and program management and implementation) and the dependent variable (soft-power leadership conceptualization among MBA students)."

Analysis related to the minor hypotheses was conducted separately on the effect of the work sector on the causal relationship paths between the three independent variables (curriculum content, learning style, and program management and implementation) and the dependent variable soft-power leadership conceptualization. To examine the effect of the work sector on the causal paths, the sample was divided into two categories: the public sector and the private sector.

Table 9. Results of Standardized Estimates

\begin{tabular}{|c|c|c|c|c|}
\hline & Public sector & & Private sector & \\
\hline Hypothesized path & Standardized estimate & P-value & $\begin{array}{l}\text { Standardized } \\
\text { estimate }\end{array}$ & P-value \\
\hline $\mathrm{C} \rightarrow \mathrm{D}$ & 0.267 & 0.128 & 0.270 & 0.069 \\
\hline $\mathrm{L} \rightarrow \mathrm{D}$ & 0.349 & 0.105 & 0.382 & 0.079 \\
\hline $\mathrm{P} \rightarrow \mathrm{D}$ & 0.023 & 0.887 & 0.342 & 0.049 \\
\hline
\end{tabular}

As shown in table (9), the extracted coefficient values for the paths between the independent variables $(\mathrm{C}, \mathrm{L}$, and P) and the dependent variable (D) were different for the public sector and the private sector.

This indicates that there would be differences in the three paths due to the moderating effect of the work sector since there is a different and significant effect among the private sector students (with a P-value of 0.049).

Further investigation indicated a moderating effect on the causal relationship between the $\mathrm{C}, \mathrm{L}$, and $\mathrm{P}$ predictors with D. However, the value of $\Delta \chi^{2}$ was 49.48 and the P-value (0.543) was not significant. This means there were no significant differences among the two categories of work sector. Differences could be found at the path levels, however. Therefore, one path coefficient was constrained to be equal over the models of the two groups (public sector and private sector), and the value of $\chi^{2}$ for the new model with the constrained path was compared with the value of $\chi 2$ for the unconstrained base model (Wang \& Shih, 2009, Taylor \& Todd, 1995).

Table 10. Results of Moderating Effects of Sector ( $\chi 2$ Difference Test)

\begin{tabular}{|c|c|c|c|c|}
\hline & $\chi^{2}$ & $\mathrm{DF}$ & $\Delta \chi^{2}$ & P-value \\
\hline $\begin{array}{l}\text { Unconstrained base } \\
\text { model }\end{array}$ & 4427.644 & 2536 & & \\
\hline $\begin{array}{l}\text { Constrained base } \\
\text { model }\end{array}$ & 4477.127 & 2587 & 49.483 & 0.543 \\
\hline Constrained paths & & & & \\
\hline $\mathrm{C} \rightarrow \mathrm{D}$ & 4430.570 & 2530 & 2.926 & 0.945 \\
\hline $\mathrm{L} \rightarrow \mathrm{D}$ & 4432.188 & 2530 & 4.544 & 0.850 \\
\hline $\mathrm{P} \rightarrow \mathrm{D}$ & 4442.221 & 2530 & 14.577 & 0.001 \\
\hline
\end{tabular}

As shown in table (10), the most significant difference between the public sector and the private sector was in the effect of path $\mathrm{P}$ on $\mathrm{D}\left(\Delta \chi^{2}=14.577, \mathrm{p}<0.001\right)$. There were no significant effects on the causal relationships between $\mathrm{C}$ and $\mathrm{D}\left(\Delta \chi^{2}=2.926, \mathrm{p}<0.954\right)$ and $\mathrm{L}$ and $\mathrm{D}(\Delta \chi 2=4.544, \mathrm{p}<0.850)$ that could be attributed to the moderating variable work sector.

Based on the results, hypothesis HO4/1 (There is no significant effect of work sector on the causal relationship between curriculum content and soft-power leadership conceptualization among MBA

students) and hypothesis HO4/2 ("There is no significant effect of work sector on the causal relationship between learning style and soft-power leadership conceptualization among MBA students") are accepted, since the P-values were 0.950 and 0.850 respectively. Hypothesis HO4/3 was rejected and the alternative hypothesis 
was accepted since the P-value was 0.001 .

This means that the moderating variable work sector only affects the causal relationship between program management/implementation and soft-power leadership conceptualization, while there is no such significant effect in the case of the other two independent variables.

The results related to detailed analysis of the different items and areas of the questionnaire, which are shown in Appendix C, indicate that students' attitudes in general, were positive toward their intellectual involvement in soft-power conceptualization, which means they have expressed a good belief in the concept and its importance in management and leadership practices. For example, the highest scores went to question D4, which was related to the necessity of the leader to be effective and charismatic (with a mean of 3.94), and question D2, which was related to the relationship between intellectual stimulation and performance of employees (with a mean of 3.92). Questions D6 and D9, which were related to balancing the objectives and values of the organization with employees' capabilities to enhance productivity, and adjusting leadership style to followers' situations and needs to capitalize on followers' different resources, both have a mean of 3.89 .

In the area of curriculum content, the highest mean score (3.73) was for question C11, which was related to the mix of lectures, textbooks, exams, term papers, and cases to build students' professional credibility, while the lowest mean score (3.33) was for $\mathrm{C} 4$, which was related to the ability of the faculty to deliver curriculums in a way that meets the objectives of the program. In the area of learning style, the highest mean score (3.69) was for item L13, which was related to the ability of the faculty to deliver course concepts and ideas credibly and in professional language, while the lowest mean score (3.21) was for item L12, which was related to the degree of class participation and argumentation.

Finally, in the area of program management and implementation, the highest mean score (3.56) was for item P6, which was related to the ability of the program to inspire the right vision to fit students' work environment, while the lowest mean score (3.38) was for item P1, which was related to the ability of the business department to manage the MBA program effectively.

\section{Discussion, Conclusion, and Implications}

\subsection{Discussion and Conclusion}

Based on the results and findings of the analysis, and referring to the problem of the study, the following conclusions may be drawn:

1. The percentage of females in the sample (53\%) was larger than that of males (47\%). Table 2 somehow projects the population distribution in most of the Jordanian universities in terms of gender since women for such cultural changes are more enthusiastic to university education, and this may be related to the megatrend that has taken place in Jordan socially and economically over the last fifteen to twenty years. $61 \%$ of the subjects came from an educational background of pure and applied sciences, such as chemistry, physics, math, engineering, medicine, and other natural sciences, while 39\% were from a social sciences background. That indicates that most of the students on MBA programs in business schools are from a scientific background, perhaps due to the opportunity the program may provide to obtain a better job in management or management-related work. In terms of the work sector, the results were skewed toward the private sector (58\%) rather than the public sector (42\%). This might be attributed to the location of the University of Jordan in Amman, the capital, where most of the big private firms and businesses are located.

2. As an overall view of the results and findings of the study, subjects had a positive conceptualization of soft-power leadership and satisfactory belief in the concept in practice, since their grand mean score was 3.8056 (table 3). As far as the influence of such variables in forming soft-power conceptualization among students is concerned, the effects of curriculum content, learning style, and the way instructors conduct their classes, as well as the way the MBA program is managed and implemented by the business departments, were found to be of a satisfactory level, since the grand mean score for the three variables was 3.46 collectively.

Concerning the standardized effects of the three variables (curriculum content, learning style, and program management and implementation) on soft-power conceptualization, it may be concluded that learning style had the highest effect on soft-power leadership conceptualization, with a mean score of 3.5031, a statistical effect (P-value) of 0.013 , and a path coefficient of 0.387 . This indicates that students were positive when asked about the effect of learning style on their conceptualization, and shows that a suitable learning method was adopted by their instructors. Curriculum content had the second-highest effect, with a mean score of 3.4774, a statistical significance (P-value) of 0.018 , and a path coefficient of 0.260 . This indicates a satisfactory level of attitudes toward the content of curriculums in terms of the materials used in class and their suitability in building the 
concept of soft-power leadership among students. Finally, program management and implementation had a positive mean score of 3.4036. This indicates that the program is managed and implemented at a satisfactory level, although this variable doesn't prove to be statistically significant in comparison to the other two variables. More efforts could be spent on this issue in the future. So in general it may be concluded that learning style and curriculum content do affect the soft-power conceptualization among MBA students, while the way the program is managed and implemented does not have that much of an effect.

This indicates that the American Model of Management Education (AMME) is to some degree applicable at a satisfactory level in the areas of curriculum content and material, and in the way, instructors are teaching their classes and interacting with students. The effect of program management and implementation on building up soft-power conceptualization among students was not significant; nevertheless, the result still shows that the American style of program management has a positive effect.

3. Concerning the effect of the moderating variable gender on the causal

relationship between curriculum content, style of learning, and program implementation, and soft-power conceptualization, it may be concluded that males were different from females in their response and attitudes, which means they look at the issue in different degrees. The results proved to be significant for two paths: learning style (P-value of 0.005) and program implementation (P-value of 0.030). This may be attributed to the variation in efforts made by the two groups in terms of class involvement and contribution, and following up with the business department for further acknowledgment about the program. No difference was found about the influence of gender on the causal relationship between curriculum content and soft-power conceptualization.

In terms of the effect of background education, it may be concluded that, based on their undergraduate education, students differed in the way they perceived the effect of curriculum content (P-value of 0.010) and how the program was managed (P-value of 0.040) on their soft-power conceptualization. This may be attributed to the big variation in the mentality of natural sciences and social sciences. No difference was found concerning the influence of educational background on the causal relationship between curriculum content and soft-power conceptualization.

Finally, the results indicate that students in the private sector and those in the public sector (P-value of 0.001) varied in the way they see the program is managed and implemented. This may also be attributed to the variation in mentality and experience among students since the private sector is way more advanced than the public sector when it comes to qualification and performance. In addition, there might be higher quality standards measurements among the private sector students. No difference was found concerning the influence of the respondent's work sector on the causal relationships between curriculum content and soft-power conceptualization or between the style of learning and soft-power conceptualization.

\subsection{Practical and Theoretical Implications of the Study:}

Based on the results and findings, the following practical and theoretical implications may be stated for the benefit of academic scholars and MBA program planners and directors, as well as faculties and administrators of business schools.

Since statistical analysis results for all variables are satisfactory, with mean scores above average based on a five-point Likert scale, all persons in charge may be advised to enhance the influence of the three independent variables in building soft-power conceptualization among graduate students, and in particular MBA students. To be more precise, implications and recommendations are as follows:

1. The results and findings indicated that the independent variables (curriculum content, style of learning, and style of program management and implementation) had a significant but not a large influence on the formation of soft-power conceptualization among students. This may be due to the absence of spiritual contact between students and instructors, and the absence of real engagement of students in the class environment, as well as the absence of a program coordinator or director. Anyway, more attention has to be given to how curriculums are designed and delivered to students, mainly about the quality of material given to students to meet their expectations, enrich their knowledge, and inspire future demand. The class environment can also be improved in terms of having a suitable size of the class, material requirements, and a positive relationship.

2. The style of teaching and the way curriculums and courses are delivered to students have to be more attention-grabbing, which is the responsibility of the person in charge of directing the program, and instructors have to be more enthusiastic in creating incentives and assigning convincing course work rewards and motivations. This will encourage and build up the skills and competencies that are needed for class contributions in discussion and argumentation. 
3. Since the mean score for the effect of program management and implementation was the lowest among the independent variables, great attention has to be paid in this regard. In general, there is a need for proper evaluation of how the program is managed, the style of supervision and guidance of students, and the way curriculums are offered quantitatively and qualitatively. Revisiting the vision of the program is necessary to make sure that it is inspirational and fits the needs of the workplace in the Jordanian market. Students also need to be informed about the objectives, vision, and philosophy of the program.

4. Theoretically, the results of the study were to some degree compatible with the results of those studies conducted in different countries in terms of the domination of AMME. The results of the study were consistent with what O'Brien (2011) found in his study on Indian business students - that the American model still dominates Indian MBA programs, and that the soft power of AMME remains dominant and expansionist. The results were also consistent with the findings of Bieber and Martens (2011). Although a dialectical tension was found between the European and American models in the field of private enterprises and schools, AMME still had the most dominant influence.

\section{References}

Anderson, J., \& Gerbing, D. (1988). Structural equation modeling in practice: A review and recommended two-step approach, Psychological Bulletin, 103(3). https://doi.org/10.1037/0033-2909.103.3.411

Bieber, T., \& Kerstin, M. (2011). OECD PISA study as a soft power in education: Lessons from Switzerland and the US. European Journal of Education, 46(1), 101-116. https://doi.org/10.1111/j.1465-3435.2010.01462.x

Byrne, B. (2010). Structural equation modeling with Amos basic concepts, application and programing (2nd ed.) Routledge Taylor. https://doi.org/10.4324/9781410600219-21

Dimock, V., \& McGree, M. (2015). Leading change from classroom: Teachers as leaders. American Institute for research.

Diplo, L. (2014). Get Your Brain in Motion.

Dougherty, J. (2013). Russian's soft power strategy, master thesis, November. unpublished, George Town University, U.S.

Dubber, J. (2015). How soft power can help meet international challenges. British Council, September, Head of Policy and External Relations and Alasdair, Donaldson, Editor.

Evans, P., \& Bob, W. (2005). Collaboration roles, Harvard Business Review, July-August.

Hair, F. (2010). Multivariate data analysis: A global perspective (7th ed.) Pearson. https://doi.org/10.1007/978-3-642-04898-2_395

Karpowicz, J. (2012). Limits to Russian soft power in the post-soviet area. DGAP Analysis, 8 July.

Lao-tsu, 630 BC.

Livingston, C. (1992). Introduction: Teacher leadership for restructuring schools, evolving roles. schools restructuring series. Washington DC, National Education Association.

Lukes, S. (2005). Power: A radical view (2nd ed.) New York: Palgrave MacMillan. (Lukes:2010:11). https://doi.org/10.2307/2065624

Marijk, V. (2016). China: A follower or leader in global higher education, February. CSHE: Center for Studies in Higher Education. University of California, Berkley.

Martin, J. (2011). hard vs. soft power in global and national politics. The International Symposium on Cultural Diplomacy. Berlin Mai 11-15, NyenMgtArtiBerlin 131(Doc).

Nye, J. J. (1990). Soft power: The Means to succeed in world politics. New York Public Affairs, 102. https://doi.org/10.1002/j.1538-165X.2004.tb01291.x

Nye, J. J. (2000). Propaganda isn't the way: soft power. International Herald Tribune, January(10). Retrieved October 21, 2013 from http://www.nytimes.com/2003/01/10/opinion/10ihtednye_ed3_.html

Nye, J. J. (2002). The Paradoxes of American power. Why the world's only superpower can't do it alone. New York: Oxford University Press. https://doi.org/10.1093/0195161106.001.0001

Nye, J. J. (2004). Soft power: The means to success in world politics. New York: Public Affairs. https://doi.org/10.1177/03058298070350020903

Nye, J. L., \& ARMITAGE, R. (2006). Commission on smart power, Center for Strategic and International 
Studies, en ligne.

Nye, J. J. (2006). Soft power, hard power and leadership. Spring. Compass: A Journal of Leadership. John F Kennedy School of Government, Harvard University. https://doi.org/10.1177/03058298070350020903

Shambaugh, D. (2013). China goes global: The partial power. Oxford University, and with the mix of enormous diaspora and Confucius philosophy, program Horizon 2020 (UNISCO, Media Services, 4-5-2017). https://doi.org/10.1080/10803920.2013.797257

Taylor, S., \& Todd, P. (1995). Understanding information technology usage: A test of competing models, INFORMS Information System Research, 6(2). https://doi.org/10.1287/isre.6.2.144

UNESCO Media Services (2017).

Wang, H., \& Chung, L. (2008). The conception of soft power and its policy implications: A comparative study of China and Taiwan, Journal of Contemporary China, ISSN 1067-0564.

Wang, Y., \& Shih, Y. (2009). Why do people use information kiosks? A validation of the unified theory of acceptance and use of technology, Governmental Information Quarterly. https://doi.org/10.1016/j.giq.2008.07.001

Wilson III, J. (2008). Hard power, soft power, and smart power. Sage Publications. https://doi.org/10.1080/10670560802000191

\section{Appendixes}

Appendix (A): Descriptive Analysis of the Questionnaire

\begin{tabular}{|c|c|c|c|c|c|c|c|c|c|}
\hline \multirow[b]{2}{*}{ Questions } & \multirow{2}{*}{$\frac{\mathrm{N}}{\text { Statistic }}$} & \multirow{2}{*}{$\begin{array}{l}\text { Minimum } \\
\text { Statistic }\end{array}$} & \multirow{2}{*}{$\begin{array}{l}\text { Maximum } \\
\text { Statistic }\end{array}$} & \multicolumn{2}{|l|}{ Mean } & \multirow{2}{*}{$\begin{array}{l}\text { Std. Deviation } \\
\text { Statistic }\end{array}$} & \multirow{2}{*}{$\frac{\text { Variance }}{\text { Statistic }}$} & \multicolumn{2}{|c|}{ Skewness } \\
\hline & & & & Statistic & Std. Error & & & Statistic & Std. Error \\
\hline D1 & 325 & 1 & 5 & 3.82 & .042 & .758 & .575 & -.795 & .135 \\
\hline D2 & 325 & 2 & 5 & 3.92 & .044 & .789 & .623 & -.312 & .135 \\
\hline D3 & 325 & 1 & 5 & 3.83 & .045 & .806 & .649 & -.425 & .135 \\
\hline D4 & 325 & 1 & 5 & 3.94 & .050 & .896 & .802 & -.507 & .135 \\
\hline D5 & 325 & 1 & 5 & 3.80 & .046 & .828 & .685 & -.499 & .135 \\
\hline D6 & 325 & 1 & 5 & 3.89 & .046 & .829 & .688 & -.634 & .135 \\
\hline D7 & 325 & 1 & 5 & 3.72 & .055 & .989 & .979 & -.442 & .135 \\
\hline D8 & 325 & 1 & 5 & 3.48 & .044 & .796 & .633 & .594 & .135 \\
\hline D9 & 325 & 1 & 5 & 3.89 & .048 & .866 & .751 & -.678 & .135 \\
\hline D10 & 325 & 1 & 5 & 3.75 & .047 & .840 & .706 & -.476 & .135 \\
\hline D11 & 325 & 1 & 5 & 3.80 & .050 & .904 & .817 & -.547 & .135 \\
\hline D12 & 325 & 1 & 5 & 3.83 & .052 & .941 & .886 & -.579 & .135 \\
\hline $\mathrm{C} 1$ & 325 & 1 & 5 & 3.42 & .054 & .968 & .936 & -.299 & .135 \\
\hline $\mathrm{C} 2$ & 325 & 1 & 5 & 3.40 & .050 & .899 & .809 & -.389 & .135 \\
\hline C3 & 325 & 1 & 5 & 3.45 & .051 & .924 & .853 & -.356 & .135 \\
\hline $\mathrm{C} 4$ & 325 & 1 & 5 & 3.33 & .051 & .919 & .844 & -.332 & .135 \\
\hline C5 & 325 & 1 & 5 & 3.49 & .048 & .866 & .751 & -.373 & .135 \\
\hline C6 & 325 & 1 & 5 & 3.51 & .052 & .932 & .868 & -.299 & .135 \\
\hline $\mathrm{C} 7$ & 325 & 1 & 5 & 3.46 & .050 & .897 & .804 & -.279 & .135 \\
\hline C8 & 325 & 1 & 5 & 3.55 & .049 & .889 & .791 & -.428 & .135 \\
\hline C9 & 325 & 1 & 5 & 3.47 & .054 & .970 & .941 & -.366 & .135 \\
\hline C10 & 325 & 1 & 5 & 3.33 & .036 & .652 & .425 & .956 & .135 \\
\hline C11 & 325 & 1 & 5 & 3.73 & .052 & .942 & .888 & -.467 & .135 \\
\hline $\mathrm{C} 12$ & 325 & 1 & 5 & 3.54 & .048 & .869 & .756 & -.450 & .135 \\
\hline C13 & 325 & 1 & 5 & 3.53 & .052 & .941 & .886 & -.485 & .135 \\
\hline L1 & 325 & 1 & 5 & 3.62 & .051 & .921 & .849 & -.450 & .135 \\
\hline $\mathrm{L} 2$ & 325 & 1 & 5 & 3.58 & .050 & .894 & .799 & -.309 & .135 \\
\hline L3 & 325 & 1 & 5 & 3.54 & .048 & .872 & .761 & -.292 & .135 \\
\hline L4 & 325 & 1 & 5 & 3.61 & .051 & .916 & .838 & -.547 & .135 \\
\hline L5 & 325 & 1 & 5 & 3.41 & .053 & .954 & .910 & -.306 & .135 \\
\hline L6 & 325 & 1 & 5 & 3.46 & .050 & .908 & .824 & -.281 & .135 \\
\hline L7 & 325 & 1 & 5 & 3.51 & .046 & .823 & 677 & -.319 & .135 \\
\hline L8 & 325 & 1 & 5 & 3.57 & .049 & .892 & .795 & -.250 & .135 \\
\hline L9 & 325 & 1 & 5 & 3.54 & .050 & .893 & .798 & -.174 & .135 \\
\hline L10 & 325 & 1 & 5 & 3.45 & .054 & .979 & .958 & -.125 & .135 \\
\hline L11 & 325 & 1 & 5 & 3.44 & .055 & .984 & .969 & -.321 & .135 \\
\hline L12 & 325 & 1 & 5 & 3.21 & .034 & 609 & .371 & .840 & .135 \\
\hline
\end{tabular}




\begin{tabular}{llllllllll}
\hline L13 & 325 & 1 & 5 & 3.69 & .053 & .951 & .905 & -.649 & .135 \\
L14 & 325 & 1 & 5 & 3.54 & .050 & .900 & .811 & -.444 & .135 \\
L15 & 325 & 1 & 5 & 3.55 & .050 & .893 & .798 & -.193 & .135 \\
P1 & 325 & 1 & 5 & 3.38 & .056 & 1.001 & 1.003 & -.218 & .135 \\
P2 & 325 & 1 & 5 & 3.42 & .053 & .948 & .898 & -.136 & .135 \\
P3 & 325 & 1 & 5 & 3.43 & .051 & .926 & .857 & -.160 & .135 \\
P4 & 325 & 1 & 5 & 3.36 & .053 & .963 & .928 & -.225 & .135 \\
P5 & 325 & 1 & 5 & 3.39 & .051 & .922 & .849 & -.250 & .135 \\
P6 & 325 & 1 & 5 & 3.56 & .053 & .956 & .914 & -.291 & .135 \\
P7 & 325 & 1 & 5 & 3.30 & .054 & .971 & .943 & -.336 & .135 \\
P8 & 325 & 1 & 5 & 3.35 & .055 & .988 & .976 & -.197 & .135 \\
P9 & 325 & 1 & 5 & 3.42 & .052 & .942 & .887 & -.419 & .135 \\
P10 & 325 & 1 & 5 & 3.43 & .055 & .990 & .980 & -.364 & .135 \\
P11 & 325 & 1 & 5 & 3.40 & .051 & .919 & .845 & -.269 & .135 \\
P12 & 325 & 1 & 5 & 3.41 & .058 & 1.049 & 1.101 & -.387 & .135 \\
Valid & $N_{325}$ & & & & & & & & \\
(listwise) & & & & & & & & & \\
\hline D: Soft pown
\end{tabular}

D: Soft power concept. C: Curriculum content. L: learning style. P: Program management.

\section{Copyrights}

Copyright for this article is retained by the author(s), with first publication rights granted to the journal.

This is an open-access article distributed under the terms and conditions of the Creative Commons Attribution license (http://creativecommons.org/licenses/by/4.0/). 